\title{
Potential Organ or Tumor Imaging Agents. 32. A Triglyceride Ester of $p$-Iodophenyl Pentadecanoic Acid as a Potential Hepatic Imaging Agent
}

\author{
S. W. SCHWENDNER ${ }^{1}$, J. P. WEICHERT ${ }^{2}$, M. A. LONGINO ${ }^{2}$, \\ M. D. GROSS ${ }^{3}$ and R. E. COUNSELL*
} Departments of ${ }^{1}$ Pharmacology and ${ }^{2}$ Radiology, The University of Michigan Medical School, Ann Arbor,
MI 48109 and ${ }^{3}$ Nuclear Medicine Unit, VA Medical Center, Ann Arbor, MI 48104, U.S.A.

(Received 2 January 1992)

\begin{abstract}
A triglyceride analog, glycerol-2-palmitoyl-1,3-di-15-( $p$-iodophenyl)pentadecanoate (DPPG) was synthesized and radiolabeled for evaluation as a potential functional liver scintigraphic agent. Uptake of DPPG was compared in normal, diabetic, tumor-bearing and heparin pretreated rats, revealing differences in uptake and clearance of radioactivity, correlating with hepatic lipase activity of these groups. Similar results were observed by $\gamma$-camera scintigraphy. Comparing the uptake of DPPG with that of its fatty acid component, 15-( $p$-iodophenyl)pentadecanoic acid (IPPA), revealed that the peak uptake of IPPA in the liver was about half that of DPPG. Based upon these findings, DPPG warrants further study as a hepatic radiodiagnostic agent.
\end{abstract}

\section{Introduction}

Currently the two most frequently used types of liver radiodiagnostics are the ${ }^{99 \mathrm{~m}} \mathrm{Tc}$-labeled sulfur colloid or microaggregated albumin and the ${ }^{99 \mathrm{~m}} \mathrm{Tc}$ labeled iminodiacetic acid (IDA) derivatives. The ${ }^{99 m}$ Tc colloids are phagocytized by the reticuloendothelial (RE) cells of the liver and spleen. Decreased hepatocellular function as in the case of malignant melanoma, portal hypotension or cirrhosis causes more radioactivity to be taken up by the spleen and bone marrow (Jost, 1987). Since the RE cells are distributed throughout the liver, scintigraphic imaging of these cells provides information about liver size, shape and position. Based on computersimulated images, it has been observed that visual assessment of liver function with Tc-colloid is systematically inaccurate, tending to underestimate poor function and to overestimate good function (Jago et al., 1987).

On the other hand, the IDA derivatives and ${ }^{131}$ Irose bengal are taken up by the hepatocyte via an anionic pathway in the same manner as bilirubin. They provide diagnostic information about the patency and the integrity of the biliary drainage

*All correspondence should be addressed to: Dr R. E. Counsell, Department of Pharmacology, M6322 Medical Science I, University of Michigan Medical School, Ann Arbor, MI 48109-0626, U.S.A. system (Chilton and Cowan, 1987). A decrease in hepatocellular function with an increase in bilirubin level causes a shift from the hepatobiliary excretion of these compounds to renal excretion, due to competition for uptake with bilirubin. Since these compounds are taken up and cleared by hepatocytes without being metabolized in these cells, they do not provide information about the metabolic status of the liver.

Several potential new agents for liver imaging are being developed, such as free fatty acid analogs, 15-( $p-\left[{ }^{123} \mathrm{I}\right]$ iodophenyl)-pentadecanoic acid (IPPA) and $17-\left[{ }^{123} \mathrm{I}\right]$ heptadecanoic acid (IHA). In addition to being developed clinically as cardiac imaging agents, these compounds are also potential hepatic imaging agents since they are taken up by the liver via the anion uptake mechanism and then metabolized by beta oxidation (Machulla and Knust, 1984). Studies with IHA in humans have shown that uptake in the liver is reduced and the residence time in the liver is increased in alcoholic patients with cirrhosis and also in patients with diabetes (Mertens et al., 1986; Hock et al., 1986).

The agents described above depend on either phagocytosis into reticuloendothelial cells or uptake into the hepatocytes via the anionic pathway. Alternative means of uptake of radiodiagnostics into the liver utilizing receptor binding have also been tested. Technitium-99m galactosyl-neoglycoalbumin is such an agent. This compound has been shown to 
bind to a receptor on the cell surface of hepatocytes (Vera et al., 1985). In addition, radioscintigraphic imaging has also been attempted using ${ }^{123}$ I-labeled very low density lipoprotein (VLDL) for uptake in the liver via the lipoprotein receptor (Huettinger et al., 1984). It was shown that $32 \%$ of the dose was taken up in the liver in the normal rabbit. This uptake was decreased when the low density lipoprotein (LDL) receptors were down-regulated with cholesterol feeding or absent as in the Watanabe-heritable hyperlipidemic rabbit. The difficulty with using such a technique in humans, however, is that the number of liver LDL receptors in the human is much lower than that in rabbits, and the clearance rate of labeled VLDL from the plasma is much slower. In addition, the ${ }^{123} \mathrm{I}$ label on the surface apoproteins is susceptible to deiodination in vivo.

It has been previously demonstrated in this laboratory that intravenous administration of radioiodinated cholesteryl iopanoate solubilized in a detergent vehicle readily associated with plasma lipoproteins in the rat. At $30 \mathrm{~min}$ following injection, approx. $31 \%$ of the radioactivity accumulated in the liver, and this concentration was seen to increase with time. Upon incorporation of this compound into chylomicron remnants, this uptake was enhanced to $87 \%$ present in the liver by $30 \mathrm{~min}$ (Damle et al., 1983). The difficulties with such a preparation are 2-fold. First, the efficiency of incorportation of the radiolabeled compound into the lipoprotein was very low. Secondly, this compound has been shown to be resistant to hydrolysis, so it would provide no information about the metabolic status of the liver.

The rationale for the present study is based upon our current understanding of mammalian lipoprotein metabolism in the liver. The plasma lipoproteins are microscopic vesicles that transport the bulk of nonpolar lipids in the form of a microemulsion, comprised of phospholipids as principal emulsifiers, and amphipathic proteins called apoproteins associated with the surface of these particles. These apoproteins function mainly as ligands for cell-surface receptors. The triglyceride-enriched lipoproteins, chylomicrons (CM) and very low density lipoproteins (VLDL), are synthesized in the intestine and the liver, respectively. Once in the circulation, much of the triglyceride is hydrolyzed by lipoprotein lipase (LPL) bound by heparin sulfate to the endothelial surface of capillaries present in peripheral tissues. The resulting smaller, remnant particle exchanges apoproteins and is then rapidly taken up in the liver by receptormediated endocytosis. Hepatic lipase (HL), an enzyme bound by heparan sulfate to the endothelial cells of the liver, facilitates the uptake of the remnant particle by the liver (Sultan et al., 1990). In a number of disease states, including alcoholism and diabetes, liver lipoprotein metabolism and HL activity are compromised.

The purpose of this study was to evaluate the potential of glycerol-2-palmitoyl-1,3-di( $p$-iodo-

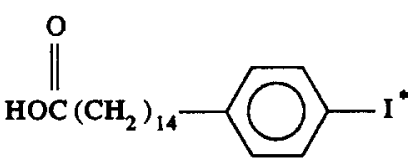

IPPA

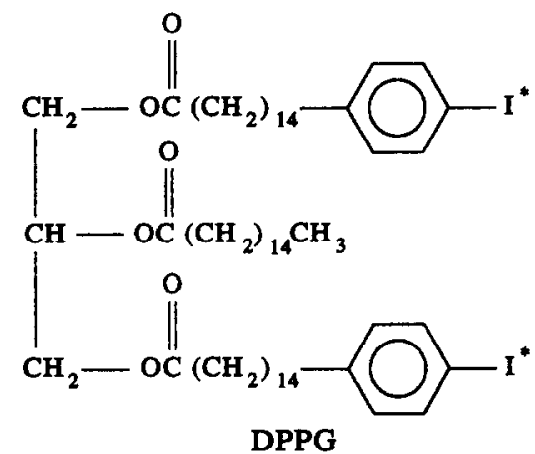

Fig. 1. Structures of 15-( $p$-iodophenyl)pentadecanoic acid (IPPA) and glycerol-2-palmitoyl-1,3-di-15-( $p$-iodophenyl)pentadecanoate (DPPG)

phenyl)pentadecanoate (DPPG) as a functional hepatic radiodiagnostic agent. This was accomplished by examining its uptake and clearance in normal and disease states. This compound would presumably be treated as an endogenous triglyceride, becoming associated with lipoprotein particles that could be taken up in the liver by specific receptors. Once taken up by the liver, it could become a substrate for liver lipases which would release IPPA for further metabolism and excretion.

\section{Materials and Methods}

Female Sprague-Dawley rats, 200-250 g (Charles River, Portage, Mich.) were used in all studies. Rats were housed in a temperature and light-controlled room. Rats had free access to food and water. Diabetes was induced by the injection of streptozotocin (Sigma, St Louis, Mo.) i.v. in $0.1 \mathrm{M}$ citrate buffer $(\mathrm{pH}=4.5)$ at a dose of $65 \mathrm{mg} / \mathrm{kg}$ body wt 3 days prior to administration of compound (Normura et al., 1982). Another group of rats was innoculated with Walker 256 carcinoma minced in saline $(1 \mathrm{~g}$ tumor $/ 10 \mathrm{~mL}$ of saline, $1 \mathrm{~mL}$ injected per rat, $>10^{6}$ cells) in the left hindlimb. These animals were used $7-10$ days later when the tumor weight averaged $10 \mathrm{~g}$. An additional group of rats was injected with heparin, $100 \mathrm{U} / \mathrm{kg}$ body wt i.v. $10 \mathrm{~min}$ prior to use (Gibson et al., 1984).

\section{Compounds}

Synthesis and radiolabeling. 15-( $p$-Iodophenyl)pentadecanoic acid (IPPA) was obtained commercially (Mara Specialty Chemicals, Philadelphia, Pa). Glycerol-2-palmitoyl-1,3-di-15-(4-iodophenyl)pentadecanoate (DPPG) was synthesized by the following method: dicyclohexylcarbodiimide $(95 \mathrm{mg}$, $0.46 \mathrm{mmol}$ ) was added to a rapidly stirring solution 
of 2-monopalmitin (Weichert et al., 1986a) $(66 \mathrm{mg}$, $0.20 \mathrm{mmol})$, IPPA $(186 \mathrm{mg}, 0.42 \mathrm{mmol}$ ) and a catalytic amount of dimethylaminopyridine $(8 \mathrm{mg})$ in anhydrous $\mathrm{CH}_{2} \mathrm{Cl}_{2}(3 \mathrm{~mL})$ under $\mathrm{N}_{2}$. The reaction mixture was stirred for $48 \mathrm{~h}$, diluted with $\mathrm{CH}_{2} \mathrm{Cl}_{2}$ $(10 \mathrm{~mL})$ and filtered to remove precipitated dicyclohexylurea. The filtrate was washed successively with $0.5 \mathrm{~N} \mathrm{HCl}(2 \times)$, saturated aqueous $\mathrm{NaHCO}_{3}(2 \times)$, $\mathrm{H}_{2} \mathrm{O}$, brine and dried $\left(\mathrm{MgSO}_{4}\right)$. Removal of solvent in vacuo afforded a white residue which was purified by column chromatography on silica gel eluted with hexanes/ethyl acetate $(5: 2)$. Combination of the appropriate fractions and removal of solvent in vacuo gave a solid (m.p. $47-48^{\circ} \mathrm{C}$ ) which was crystallized from acetone to give the title compound: yield $147 \mathrm{mg}$ $(62 \%)$; m.p. $50-51^{\circ} \mathrm{C}$; HPLC (IBM $5 \mu \mathrm{m}$ silica gel column, $10 \% \mathrm{EtOAc} / \mathrm{Hex}) K^{\prime}=0.36$; TLC (silica gel, $28 \% \mathrm{EtOAc} / \mathrm{Hex}) R_{\mathrm{f}}=0.61$. Analysis calculated for $\left(\mathrm{C}_{61} \mathrm{H}_{100} \mathrm{I}_{2} \mathrm{O}_{6}\right): \mathrm{C}, 61.92 ; \mathrm{H}, 8.52 ; \mathrm{I}, 21.45$. Found: C, 62.03; H, 8.56; I, 21.35. IPPA and DPPG were both radiolabeled with ${ }^{125}$ I (Amersham, Arlington Heights, Ill.) by the pivalic acid melt procedure (Weichert et al., 1986b) for tissue distribution studies and rat scanning studies. In addition, DPPG was radiolabeled with ${ }^{123}$ I (Atomic Energy of Canada Limited, Vancouver, B.C.) by the same procedure for the imaging studies in the dog.

Formulation. For administration, IPPA was dissolved in ethanol, then $2 \%$ bovine serum albumin (BSA) in water was added to a final ethanol concentration of $10 \%$. DPPG was dissolved in hexane or benzene and Tween 20 (polyoxyethylene sorbitan monolaurate) was added $(0.1 \mathrm{~mL} / \mathrm{mg}$ of compound), and the solvent evaporated under a stream of nitrogen with gentle heating. Physiological saline was added to give a final Tween 20 concentration of $1-3 \%$. Any remaining solvent was then evaporated until the solution cleared. Both formulated compounds were extruded through $0.22 \mu \mathrm{m}$ Millex $\mathrm{HV}$ filters (Millipore, Bedford, Mass.) prior to administration to animals. Prior to use, the compounds were assayed for radioactivity using a Searle 1185 $\gamma$-counter $\left(84-86 \%\right.$ counting efficiency for $\left.{ }^{125} \mathrm{I}\right)$. Radiochemical purity was assessed by thin layer chromatography (TLC) using hexanes:ethyl acetate $(5: 2, v / v)$ for DPPG and methylene chloride: methanol $(95: 5, \mathrm{v} / \mathrm{v})$ for IPPA. In all cases, greater than $95 \%$ of the radioactivity comigrated with the standard.

Tissue distribution. Rats were lightly anesthetized with ether prior to intravenous administration of radiolabeled compound $(3.4-18.1 \mu \mathrm{Ci}$, $0.009-0.075 \mu \mathrm{mol})$. At $5,30,60 \mathrm{~min}$ or $24 \mathrm{~h}$ following administration, the rats were again anesthetized and sacrificed by cardiac puncture. Blood was collected in a vacutainer tube containing heparin. Blood samples were taken for counting and the blood was centrifuged at $800 \mathrm{~g}$ for $10 \mathrm{~min}$ to obtain plasma. The following organs were removed, rinsed of blood and blotted dry: adrenal, fat, heart, kidney, liver, lung, muscle, ovary, spleen, thyroid and tumor (where applicable). Whole organ weights were taken of liver, spleen and tumor. Large organs were minced with scissors and portions taken for weighing. All tissue samples were weighed in tared cellulose acetate capsules and then assayed for radioactivity. Results are expressed as \% administered dose/g tissue and as \% administered dose/organ.

Polyacrlyamide gel electrophoresis ( $P A G E$ ). Plasma samples were analyzed (Narayan, 1975) to determine the association of radioactivity with plasma proteins and lipoproteins. Gels were run and cut as described previously (Counsell et al., 1989).

Lipid extraction. Samples of liver and plasma were homogenized in chloroform:methanol (Folch et al., 1957). Following homogenization and extraction, the organic phase was analyzed by TLC developed in either hexanes: ethyl acetate $(5: 2, \mathrm{v} / \mathrm{v})$ for DPPG or methylene chloride:methanol $(95: 5, \mathrm{v} / \mathrm{v})$ for IPPA. TLC results are expressed as the \% of total radioactivity comigrating with an unlabeled standard of either free acid or the triglyceride ester.

Biochemical assays. To verify the validity of the various animal models of liver dysfunction utilized in this study, biochemical parameters were measured in rats from all treatment groups. Plasma glucose, triglyceride, protein and SGOT were determined using kits from Sigma (St Louis, Mo.), and total cholesterol was determined with a kit from Worthington (Freehold, N.J.).

Heparin-releasable hepatic lipase (HL) was measured using liver homogenates incubated with heparin (Persson and Nilsson-Ehle, 1990). These samples were assayed for lipase activity (NilssonEhle and Eckman, 1977). Results are expressed as nanomoles fatty acid released per hour.

\section{Gamma camera imaging}

Rats with [25I]DPPG. Scanning of rats was done with an Ohio Nuclear Mobile Camera, using a high sensitivity-low energy collimator. Rats were sedated with $87 \mathrm{mg} / \mathrm{kg}$ ketamine and $13 \mathrm{mg} / \mathrm{kg}$ xylazine, i.m., positioned supine on the inverted camera face, then injected with compound $(28.8-53.9 \mu \mathrm{Ci}$, $0.135-0.324 \mu \mathrm{mol})$. Images were accumulated at intervals out to $90 \mathrm{~min}$ following administration of compound. Next, animals were injected with ${ }^{99 m} \mathrm{Tc}-$ microaggregated albumin (Microlite, DuPont-NEN Medical Products, Boston, Mass.) and an image accumulated without shifting the position of the animal. Region-of-interest calculations were later performed by drawing a $15 \times 15$ pixel square over the ${ }^{99} \mathrm{~m}$ Tc liver image. Another square was drawn over the heart to measure blood pool activity. The accumulated radioactivity in these regions in all scans was determined to give the percent of total activity and plotted as a function of time.

Dog with [ $\left.{ }^{223} I\right] D P P G$. A female mongrel dog weighing $40 \mathrm{~kg}$ was sedated with pentobarbitol for the course of the imaging experiment. The dog 
Table 1. Tissue distribution of DPPG in the rat

\begin{tabular}{lcccc}
\hline Tissue & $\begin{array}{c}5 \mathrm{~min} \\
(n=4)\end{array}$ & $\begin{array}{c}30 \mathrm{~min} \\
(n=4)\end{array}$ & $\begin{array}{c}60 \mathrm{~min} \\
(n=3)\end{array}$ & $\begin{array}{c}24 \mathrm{~h} \\
(n=3)\end{array}$ \\
\hline Adrenal & $3.51 \pm 0.24^{*}$ & $2.86 \pm 0.11$ & $1.98 \pm 0.40$ & $1.57 \pm 0.07$ \\
Blood & $1.20 \pm 0.12$ & $2.08 \pm 0.17$ & $1.16 \pm 0.26$ & $0.12 \pm 0.03$ \\
Fat & $0.28 \pm 0.06$ & $0.66 \pm 0.13$ & $0.26 \pm 0.03$ & $0.46 \pm 0.07$ \\
Heart & $1.35 \pm 0.09$ & $1.46 \pm 0.06$ & $0.75 \pm 0.18$ & $0.09 \pm 0.02$ \\
Kidney & $0.70 \pm 0.08$ & $0.71 \pm 0.03$ & $0.59 \pm 0.08$ & $0.14 \pm 0.01$ \\
Liver & $7.04 \pm 0.26$ & $4.16 \pm 0.15$ & $1.46 \pm 0.37$ & $0.24 \pm 0.03$ \\
Lung & $4.62 \pm 0.34$ & $3.46 \pm 0.17$ & $1.22 \pm 0.68$ & $1.31 \pm 0.07$ \\
Muscle & $0.13 \pm 0.01$ & $0.16 \pm 0.02$ & $0.13 \pm 0.04$ & $0.05 \pm 0.00$ \\
Ovary & $1.12 \pm 0.16$ & $1.03 \pm 0.03$ & $1.05 \pm 0.18$ & $0.48 \pm 0.12$ \\
Spleen & $0.94 \pm 0.05$ & $0.86 \pm 0.04$ & $0.43 \pm 0.07$ & $0.09 \pm 0.01$ \\
Thyroid & $2.33 \pm 0.41$ & $14.13 \pm 1.96$ & $176.8 \pm 59.0$ & $175.7 \pm 19.5$ \\
\hline R Results & &
\end{tabular}

*Results expressed as mean \% administered dose per gram tissue + SEM.

received, intravenously, $2.5 \mathrm{mCi}\left[{ }^{123} \mathrm{I}\right] \mathrm{DPPG}$ formulated in Tween-saline. Images were accumulated on a Picker Dyna 4/15 Gamma Camera out to $90 \mathrm{~min}$ post-injection. At this time a dose of ${ }^{99 \mathrm{~m}} \mathrm{Tc}$-microaggregated albumin was administered and an image accumulated. Region-of-interest accumulations were determined as described above.

\section{Results and Discussion}

\section{Comparison of DPPG to triolein and tripalmitin as a} substrate for $H L$

DPPG was compared to radiolabeled triolein and tripalmitin as a substrate for $\mathrm{HL}$. While triolein had a greater $V_{\max }$ than both tripalmitin and DPPG with values of $34.84,8.34$ and $11.64 \mathrm{nmol} / \mathrm{h}$, respectively, the $K_{\mathrm{m}}$ values were $370.37 \mathrm{nmol}$ for triolein, $312.50 \mathrm{nmol}$ for tripalmitin and $400 \mathrm{nmol}$ for DPPG. This indicates that DPPG is similar to tripalmitin as a substrate for this enzyme, but is not as good a substrate as triolein. These results appear to agree with the reported 3- to 7-fold increase in activity seen

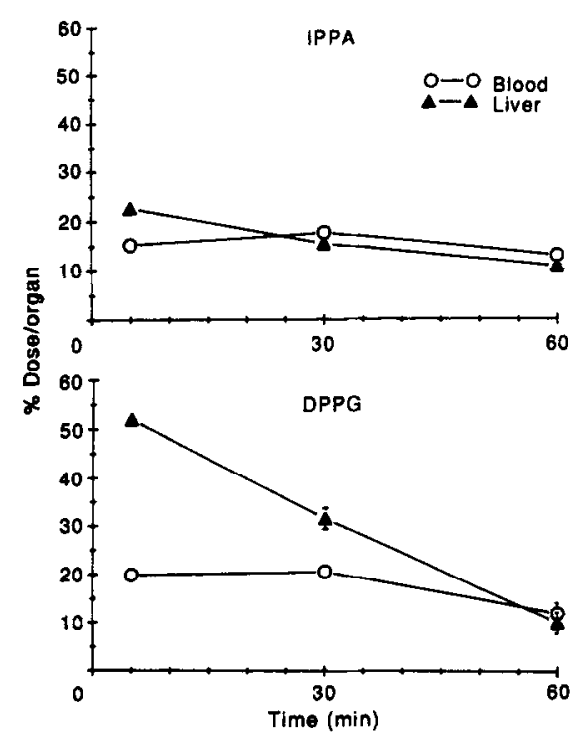

Fig. 2. Uptake of either IPPA or DPPG in the blood and liver of the rat at various times post-injection. Results are expressed as the mean percent dose taken up per whole organ \pm SEM, $n=3-4$ animals per time point. when triolein was used as a substrate compared to tripalmitin for either LPL (Wang et al., 1982) or HL (Masuno and Okuda, 1986).

\section{Uptake of DPPG and IPPA in untreated rats}

DPPG administered to untreated rats showed the pattern of uptake seen in Table 1 . The maximum liver uptake was seen at $5 \mathrm{~min}$ and corresponded to $52 \%$ of the administered dose (Fig. 2). While the free fatty acid is known to accumulate in the heart, this is not seen with administration of the triglyceride even at 1 or $2 \mathrm{~min}$ following administration of the compound (results not shown). The increasing levels of activity seen in the thyroid with time indicate that metabolism and deiodination of the compound are occurring within $30 \mathrm{~min}$ following administration.

Similar to DPPG, rats given IPPA showed the greatest level of radioactivity in the liver at $5 \mathrm{~min}$ (Fig. 2). However, this value was approximately one half that seen for DPPG. The levels of radioactivity in the blood following administration of IPPA were similar to that seen for DPPG over the same timecourse (Fig. 2).

As can be seen in Table 2, distribution of radioactivity in the various plasma compartments for the rats given IPPA was found to differ significantly from that of rats given DPPG. PAGE analysis revealed most of the radioactivity $(75 \%)$ was associated with the albumin fraction following administration of IPPA, indicating that most of the radioactivity was still present as the free fatty acid. On the other hand, DPPG administration resulted in greater than $50 \%$ of the radioactivity associated with lipoproteins by $5 \mathrm{~min}$.

Table 2. Polyacrylamide gel electrophoresis (PAGE) of plasma samples from rats administered either IPPA or DPPG at $5 \mathrm{~min}$ post-injection

\begin{tabular}{lcc}
\hline & $\begin{array}{c}\text { IPPA } \\
(n=3)\end{array}$ & $\begin{array}{c}\text { DPPG } \\
(n=4)\end{array}$ \\
\hline Stacking gel & $3.6 \pm 0.7 \dagger$ & $6.3 \pm 2.1$ \\
LDL & $1.2 \pm 0.2^{* *}$ & $14.8 \pm 2.4$ \\
HDL & $13.9 \pm 8.1^{*}$ & $35.1 \pm 1.9$ \\
Albumin & $75.0 \pm 9.6^{*}$ & $37.0 \pm 5.1$ \\
Below albumin & $6.3 \pm 1.0$ & $6.7 \pm 2.5$ \\
\hline
\end{tabular}

* $P<0.05$ vs rats administered DPPG; ** $P<0.01$ vs rats administered DPPG.

tResults expressed as mean percent of total radioactivity applied to gel \pm SEM. 

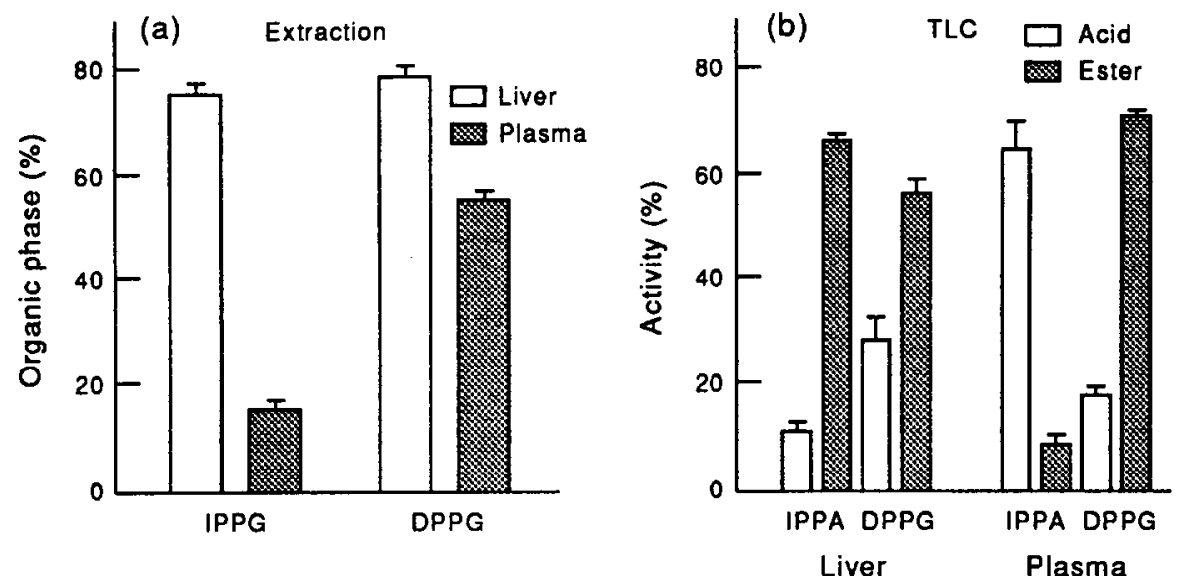

Fig. 3. (a) Lipid extraction of liver and plasma from rats given either IPPA or DPPG at $5 \mathrm{~min}$ post-injection. Results are expressed as the mean percent of radioactivity extractable into the organic phase \pm SEM for $n=34$ animals. (b) TLC of the organic phase extract from these animals. Results are expressed as the mean percent of total radioactivity that comigrated either with the free acid or with the tryglyceride ester \pm SEM for $n=3-4$ animals.

However, an additional $37 \%$ of the plasma radioactivity was found in the albumin fraction, suggesting that some hydrolysis of the radiolabeled triglyceride had occurred. With time, the percent radioactivity associated with the albumin band increased.

As can be seen in Fig. 3, analysis of the liver extraction following administration of IPPA revealed that over $66 \%$ of the lipid extractable radioactivity was in an esterified form (TLC migration was similar to that of triglyceride and cholesteryl esters) and far exceeded that present as the free acid. It therefore appears that IPPA was rapidly esterified upon entry into the liver. On the other hand, TLC analysis of the radioactivity in the plasma showed the IPPA to be largely present as the free fatty acid. The predominant form of radioactivity in the liver following DPPG administration was the esterified form and these esters gave rise to the free acid with time. Similarly, at early times radioactivity extracted from the plasma of rats receiving DPPG was primarily in the triglyceride fraction. This decreased with time, concurring with the decreased fraction of radioactivity seen migrating with lipoproteins on PAGE analysis.

\section{Comparison of animal models}

In order to determine whether the uptake seen in normal animals would be altered in disease states, animal models with disrupted liver function and altered lipoprotein metabolism were studied. These included streptozotocin-induced diabetic rats, rats bearing a Walker 256 tumor implanted in the thigh and rats pretreated with heparin.

Human type I diabetics have been reported to have an increased serum total triglyceride level, especially VLDL triglyceride. This is thought both to be due to increased synthesis of VLDL in the liver and decreased clearance. This decreased clearance is due to decreases in adipose and muscle LPL, causing decreased removal of triglyceride, and an increasing plasma $T_{1 / 2}$ of the VLDL particle. In addition, diabetic rats have been shown to secrete VLDL lacking apoE and apoC (Berry et al., 1981). Also, it has been suggested that the apoproteins in diabetics have increased glycosylation, reducing their recognition by receptors.

The presence of tumors in humans and experimental animals has been widely reported to be associated with an increase in plasma triglyceride levels and alterations in the lipoproteins, especially an increase in VLDL. This increase in VLDL triglyceride is thought to be due to decreased lipolysis by LPL. It has been demonstrated that tumor necrosis factor (also known as cachetin) is secreted by activated macrophages, and causes a suppression of LPL activity by decreasing the synthesis of the enzyme in

Table 3. Anatomical and biochemical factors of the rat treatment groups

\begin{tabular}{lcccc}
\hline Treatment group & Control & $\begin{array}{c}\text { Streptozotocin- } \\
\text { diabetic }\end{array}$ & $\begin{array}{c}\text { Tumor- } \\
\text { bearing }\end{array}$ & $\begin{array}{c}\text { Heparin- } \\
\text { treated }\end{array}$ \\
\hline Organ weight $(\mathrm{g})$ & $(n=14)$ & $(n=15)$ & $(n=13)$ & $(n=12)$ \\
Liver & $7.37 \pm 0.13 \dagger$ & $5.88 \pm 0.15^{* *}$ & $8.96 \pm 0.33^{* * *}$ & $7.28 \pm 0.26$ \\
Spleen & $0.46 \pm 0.02$ & $0.45 \pm 0.03$ & $1.14 \pm 0.07^{* * *}$ & $0.44 \pm 0.01$ \\
Glucose $(\mathrm{mg} / \mathrm{dL}) \ddagger$ & $151 \pm 2$ & $486 \pm 26^{* *}$ & $168 \pm 15$ & $162 \pm 5$ \\
Triglyceride $(\mathrm{mg} / \mathrm{dL})$ & $70 \pm 5$ & $186 \pm 48^{*}$ & $73 \pm 20$ & $28 \pm 2^{* *}$ \\
Cholesterol $(\mathrm{mg} / \mathrm{dL})$ & $68 \pm 3$ & $77 \pm 5$ & $76 \pm 4$ & $67 \pm 6$ \\
SGOT $(\mathrm{U} / \mathrm{mL})$ & $34 \pm 2$ & $57 \pm 4^{* *}$ & $81 \pm 5^{* *}$ & $36 \pm 4$ \\
\hline
\end{tabular}

${ }^{*} P<0.05$ vs control rats; ${ }^{* *} P<0.01$ vs control rats; ${ }^{* * *} P<0.001$ vs control rats.

$\nmid$ Results expressed as mean \pm SEM.

in = 5-6 for all groups for measurement of plasma glucose, triglyceride, cholesterol and SGOT. 
adipose tissue (Beutler and Cerami, 1987). Along with the decrease in LPL activity in adipose, it has been demonstrated that LPL activity was increased in heart and tumor, leading to an overall increase in post-heparin plasma LPL in mice bearing Ehrlich ascites tumor (Balint and Holtzinger, 1984). This increase in LPL activity in post-heparin plasma, along with a decrease in $\mathrm{HL}$ activity, has also been reported in patients with a variety of cancers, including stomach, lung and pancreas, among others, either with or without metastasis to the liver (Masuno and Okuda, 1985).

Administration of heparin can also alter lipoprotein metabolism as both LPL and HL are bound to the endothelial surface by heparin sulfate. Thesc enzymes are released into the circulation upon treatment with heparin, by non-specifically binding to the polysaccharide. It has been demonstrated that administration of heparin in humans results in a reduction of the total plasma triglyceride, cholesterol and phospholipid. This is due to increased catabolism of triglyceride-rich lipoproteins, decreasing VLDL cholesterol, protein and triglyceride by $50 \%$ and increasing LDL and HDL protein and cholesterol levels (Aviram et al., 1986). Modifications of the lipoprotein patterns seen in normal controls given heparin are similar to those seen in early stage chronic alcoholics (without administration of heparin) (Sasso et al., 1985).

Initially, certain physical and biochemical parameters were measured. As can be seen in Table 3, the weight of the liver was significantly decreased in the

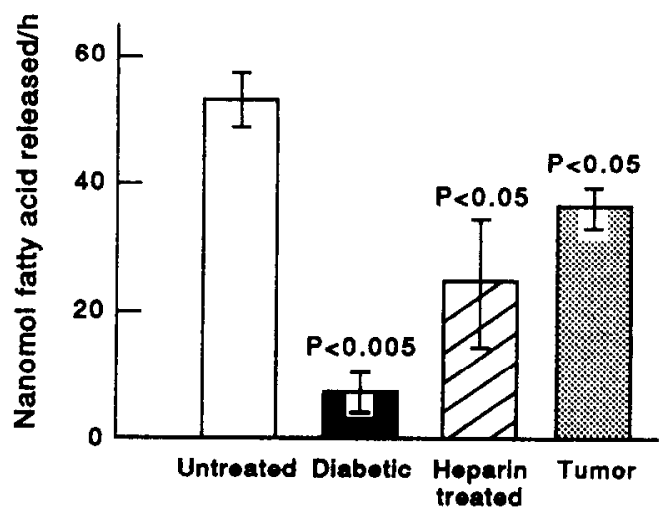

Fig. 4. Heparin-releasable hepatic lipase levels in different rat treatment groups. Results are expressed as the mean nanomoles of fatty acid released per hour \pm SEM, $n=3$.

diabetic rats, while their spleen weight remained similar to control. The tumor-bearing rats showed both an increased liver and spleen weight. This increase in liver size in the presence of Walker 256 tumor has been previously noted, however it was also reported that the weight of the liver expressed as the $\%$ of non-tumorous body weight correlated with the tumor weight (Tayek et al., 1986). There was no difference from control rats in liver or spleen weight for the heparin-treated group as would be expected from an acute treatment.

In addition to these anatomical changes, differences in biochemical parameters were observed in these animal models. The streptozotocin-diabetic rats
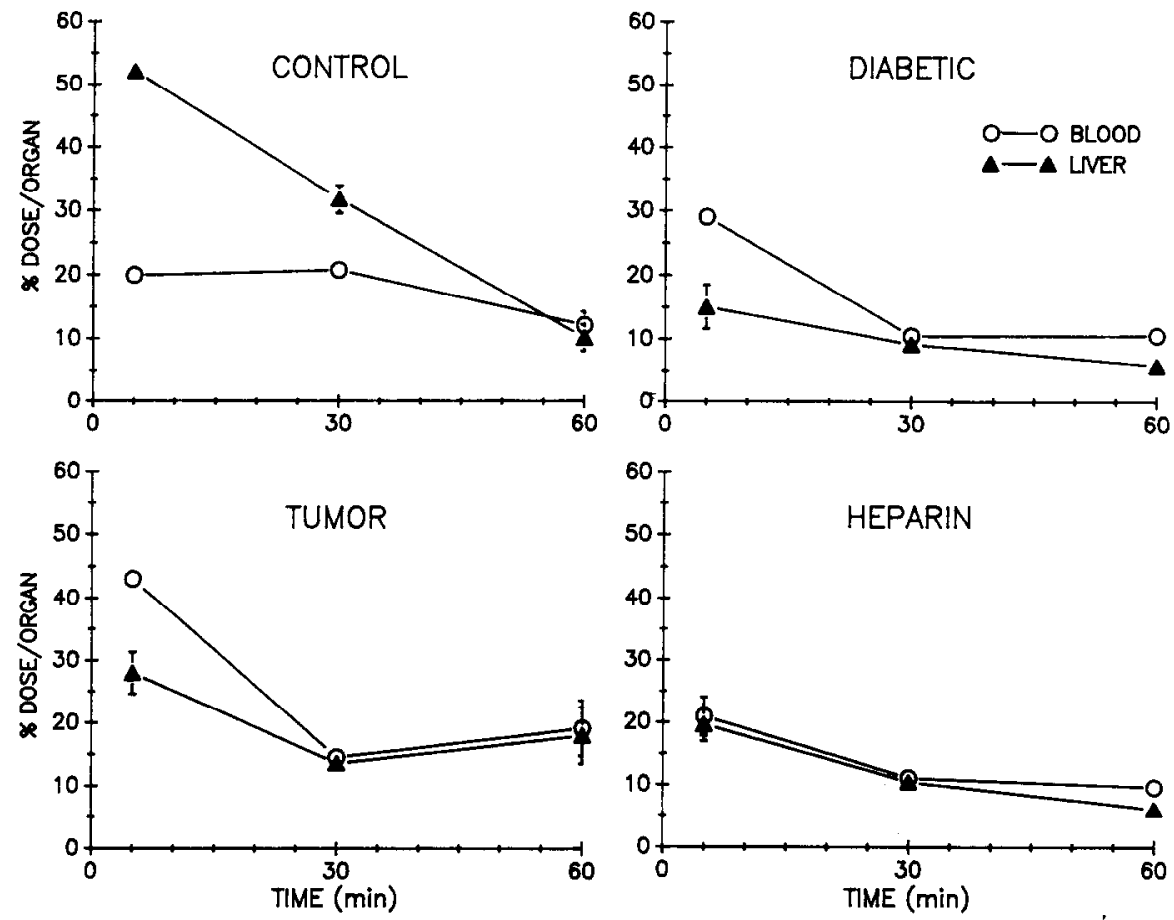

Fig. 5. Uptake of radioactivity in the blood and liver of treated rats at various times post-injection. Results are expressed as the mean percent dose taken up per whole organ $\pm S E M, n=3-4$. 
Table 4. Polyacrylamide gel electrophoresis (PAGE) of plasma samples from different treatment groups at 5 min following administration of DPPG

\begin{tabular}{lcccc}
\hline & $\begin{array}{c}\text { Control } \\
(n=4)\end{array}$ & $\begin{array}{c}\text { Streptozotocin- } \\
\text { diabetic } \\
(n=3)\end{array}$ & $\begin{array}{c}\text { Tumor- } \\
\text { bearing } \\
(n=3)\end{array}$ & $\begin{array}{c}\text { Heparin- } \\
\text { treated } \\
(n=3)\end{array}$ \\
\hline Stacking gel & $6.3 \pm 2.1 \dagger$ & $6.6 \pm 4.3$ & $4.8 \pm 1.3$ & $9.4 \pm 0.8$ \\
LDL & $14.8 \pm 2.4$ & $23.1 \pm 3.0$ & $24.4 \pm 2.4^{*}$ & $7.2 \pm 0.6^{*}$ \\
HDL & $35.1 \pm 1.9$ & $44.9 \pm 2.3^{*}$ & $35.7 \pm 3.9$ & $33.0 \pm 5.1$ \\
Albumin & $37.0 \pm 5.1$ & $14.5 \pm 0.7^{*}$ & $22.3 \pm 1.7$ & $45.9 \pm 5.5$ \\
Below albumin & $6.7 \pm 2.5$ & $11.0 \pm 2.7$ & $12.8 \pm 1.5$ & $4.3 \pm 0.6$ \\
\hline
\end{tabular}

$* P<0.05$ vs control rats.

$\nmid$ Results expressed as mean percent of total radioactivity applied to gel \pm SEM.

showed a 3-fold increase in plasma glucose over normal animals. This treatment group also had more than double the plasma triglyceride of control, while the heparin-treated group had a 3 -fold decrease. The triglyceride levels of the tumor-bearing animals fell over a wide range of values, however, no correlation could be found between plasma triglyceride levels and the size of each animal's tumor. Plasma protein and cholesterol levels were similar for all treatment groups. SGOT levels showed a significant increase in the diabetic group and was more than doubled in tumor-bearing rats, indicating hepatocellular injury. As can be seen in Fig. 4, there were also significantly lower $\mathrm{HL}$ activities of both the streptozotocin-diabetic and tumor-bearing rats when compared with the control animals.

These changes in diabetic animals at 3 days after administration of streptozotocin are in agreement with many reports for this animal model (Takanashi et al., 1987). Some investigators have reported a moderate hypercholesterolemia in addition to the pronounced hypertriglyceridemia (Redgrave and Snibson, 1977; Brown et al., 1967). The changes seen in the tumor-bearing animals were also in agreement with the reported hypertriglyceridemia and decreased LPL and HL activity seen with a variety of tumors (Masuno et al., 1985). In addition, the hypotriglyceridemia present in the heparin-treated rats was as expected (Sasso et al., 1985).

\section{Comparison of tissue disposition of DPPG in different animal models}

Each of the three treatment groups showed significantly lower uptake of radioactivity in the liver at both 5 and $30 \mathrm{~min}$, following administration of DPPG (Fig. 5). By 60 min the liver values for each group were not significantly different. Both the diabetic and tumored rats showed increased blood levels of radioactivity at $5 \mathrm{~min}$, but all three treatment groups showed significantly decreased blood levels at $30 \mathrm{~min}$. At early time periods, the liver radioactivity in the diabetic group was significantly lower than the blood levels. This is in good agreement with reports of the uptake of radiolabeled triglyceride incorporated into lipoproteins prior to administration to rats (Redgrave and Snibson, 1967; Levy et al., 1985; Bar-On et al., 1984).

The decreased uptake in the fat, heart and liver of the tumor-bearing rats corresponds to the decreased LPL and HL activity in these animals. Interestingly, the tumor does not take up much of the radioactivity associated with DPPG, although Walker 256 cells have been reported to have LPL activity (Kralovic et al., 1977). Moreover, it has been reported that

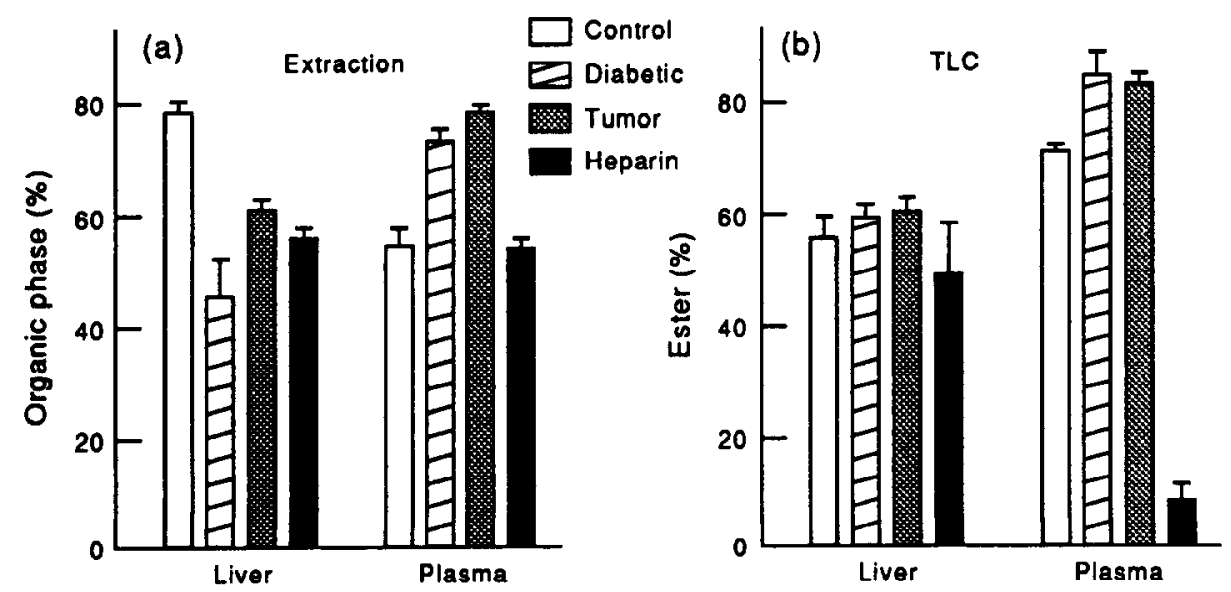

Fig. 6. (a) Lipid extraction of liver and plasma from treated rats given DPPG at 5 min post-injection. Results are expressed as the mean percent of radioactivity extractable into the organic phase \pm SEM for $n=3-4$ animals. (b) TLC of the organic phase extract from these animals. Results are expressed as the mean percent of total radioactivity that comigrated either with the free acid or with the triglyceride ester \pm SEM for $n=3-4$ animals. 
plasma VLDL triglyceride removal was decreased in tumor-bearing mice, with a small accumulation in the tumor due to VLDL triglyceride (Lyon et al., 1982).

When the distribution of radioactivity in the plasma was analyzed (Table 4), the diabetic group showed more radioactivity in the HDL fraction and less in the albumin fraction than control animals at $5 \mathrm{~min}$. This change in PAGE profile was also seen at 30 and $60 \mathrm{~min}$. The banding pattern seen in tumorbearing animals was not significantly different from control rats except for an increase in the radioactivity comigrating with LDL. Conversely, heparintreated rats demonstrated a significant decrease in LDL-associated activity at $5 \mathrm{~min}$.

Figure 6 illustrates the results obtained from lipid extraction of liver and plasma along with TLC analysis of the extract. At early time periods, all treatment groups displayed decreased levels of extractable activity in the liver. However, the percentage of this extractable radioactivity that migrated with DPPG on TLC was not significantly different for all groups.

Similar analysis of the plasma revealed that the levels of lipid extractable radioactivity were significantly higher for the diabetic and tumored animals at $5 \mathrm{~min}$. Moreover, the predominant form of this radioactivity comigrated with DPPG. However, much less activity remained in the esterified form in the heparintreated animals. In this group there was a decrease in lipid extractable radioactivity with time.

\section{Gamma camera scintigraphy of $\left[^{125} I\right] D P P G$ in untreated and diabetic rats}

Comparison of the image obtained $15 \mathrm{~min}$ following administration of DPPG to an untreated rat (Fig. 7) with that obtained with ${ }^{99 \mathrm{~m}} \mathrm{Tc}$ demonstrated good agreement in the general shape of the liver. Radioactivity was observed to clear from the left lobes of the liver into the right side, indicating clearance of activity into the GI tract with time. This was verified by sacrificing the animal while still in

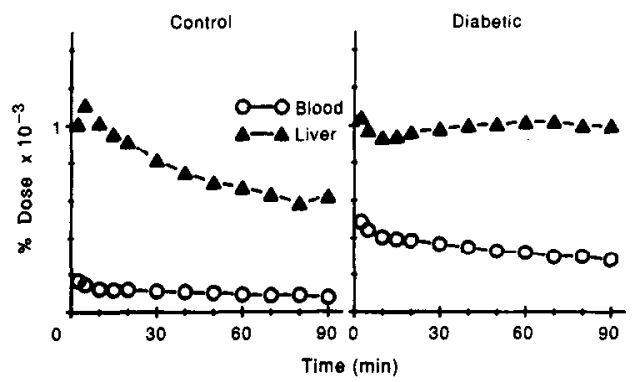

Fig. 8. Comparison of the uptake in regions of interest of images obtained by $\gamma$-camera scintigraphy of ${ }^{125} \mathrm{I}$-labeled DPPG administered either to normal or diabetic rats. The regions of interest were obtained by placing a $15 \times 15$ pixel cursor over the central region of the liver as determined by the ${ }^{90 \mathrm{~m}} \mathrm{Tc}$ image and another cursor over the heart region. The results are expressed as the percent of total radioactivity in the image present in the area of each cursor.

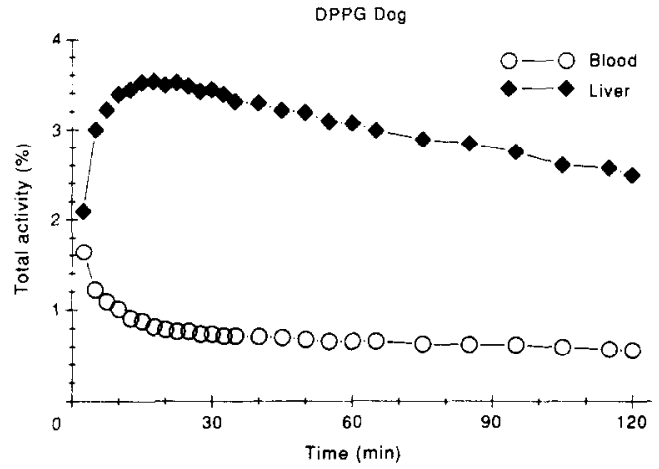

Fig. 10. Comparison of the uptake in regions of interest of images obtained by $\gamma$-camera scintigraphy of ${ }^{123} \mathrm{I}$-labeled DPPG administered to the dog. The regions of interest were obtained by placing a $15 \times 15$ pixel cursor over the central region of the liver as determined by the ${ }^{99 \mathrm{~m}} \mathrm{Tc}$ image and another cursor over the heart region. The results are expressed as the percent of total radioactivity in the image present in the area of each cursor

position on the camera, removing the liver but leaving the GI tract intact, and rescanning the animal. In addition, if the GI tract was removed and placed on the camera without the rat, the intestine, particularly that section of the duodenum proximal to the stomach was visualized (results not shown). Thus, the radioactivity appears to be clearing via the biliary tree. It is important to note for this comparison, however, that ${ }^{125} \mathrm{I}$ is a very weak $\gamma$-emitter $(28 \mathrm{keV})$ when compared to ${ }^{99 \mathrm{~m}} \mathrm{Tc}(140 \mathrm{keV})$ which accounts for the much sharper image seen with the latter.

When a diabetic rat was given DPPG and subjected to $\gamma$-camera scintigraphy, it demonstrated decreased liver uptake compared to that seen for the untreated rat. In addition, it showed a great deal of activity in the blood pool for the entire scan time. This activity did not clear with time (Fig. 8).

\section{Gamma camera scintigraphy of $\left.{ }^{123} I\right] D P P G$ in the dog}

It has been reported that the rat, dog and human have similar levels of hepatic lipase (Jansen and Hulsmann, 1985). A dog was given DPPG radiolabeled with ${ }^{123}$ I in a Tween-saline vehicle. As can be seen in Fig. 9, uptake of radioactivity occurred in the liver at $25 \mathrm{~min}$ post-injection, although radioactivity remained in the blood. With time, the activity in the liver was seen to shift into the gall bladder and gut. This uptake and clearance was graphed in Fig. 10. The pattern of uptake and clearance was very similar to that seen in the rat, although slightly delayed.

Thus, the radioiodinated triglyceride, DPPG, has been shown here to rapidly become associated with plasma lipoproteins upon administration. This compound is rapidly taken up in the liver, and the associated radioactivity clears the liver with time. In comparing the liver uptake of DPPG with the fatty acid, IPPA, twice as much DPPG is taken up in the liver versus the IPPA. When DPPG was administered to diabetic, tumor-bearing or heparin-treated rats, 


$\frac{11}{11018}$
$10 \cdot 10$.
$10-10$


the liver uptake was decreased and the clearance was altered. These results were confirmed by $\gamma$-camera scintigraphy. Also, while these animals demonstrated alterations in their scintigraphic images with DPPG, ${ }^{99} \mathrm{~m} \mathrm{Tc}$-microaggregated albumin images in the same animals showed no detectable change in uptake. Moreover, DPPG was evaluated and found to be a substrate for HL. Those animal groups with decreased HL activity also showed a decreased liver uptake of DPPG. In addition, $\gamma$-camera scintigraphy with DPPG showed a similar pattern of uptake and clearance of radioactivity in the dog.

These preliminary findings demonstrate that DPPG is treated in a manner similar to endogenous triglycerides and that a radiolabeled triglyceride analog such as that described here could be used to non-invasively monitor the status of liver lipid metabolism which is disrupted in a number of disease states. Further studies are now in progress to assess the value of DPPG as a functional hepatic imaging agent.

Acknowledgements-The authors wish to thank Ms Edie Quenby and Ms Maria Miletto for their technical assistance and Ms Pat Gannon for her assistance in the imaging studies. This research was supported by a grant from the National Institutes of Health (CA-08349).

\section{References}

Aviram M., Rosenblat M., Potesman M., Dankner G. and Brook J. G. (1986) Plasma lipoprotein and platelet function after heparin injection: studies in normal fasted and postprandial and in type $\mathrm{V}$ hyperlipoproteinemic subjects. Biochem. Med. Metabol. Biol. 35, 279-292.

Balint Z. and Holczinger L. (1984) Changes in lipoprotein lipase activity (LPLA) in tumor cells and tissues in mice bearing Ehrlich ascites tumor. Bull. Cancer 71, 412-418.

Bar-On H., Levy E., Oschry Y., Ziv E. and Shafrir E. (1984) Removal defect of very-low-density lipoproteins from diabetic rats. Biochim. Biophys. Acta 793, 115-118.

Berry E. M., Ziv E. and Bar-On H. (1981) Lipoprotein secretion by isolated perfused livers from streptozytocin-diabetic rats. Diabetologia 21, 402-408.

Beutler B. and Cerami A. (1987) Cachetin: more than a tumor necrosis factor. N. Engl. J. Med. 316, 379-385.

Brown D. F., Daudiss K. and Durrant J. (1967) Triglyceride metabolism in the alloxan-diabetic rat. Diabetes 16 , 90-95.

Chilton H. M. and Cowan R. J. (1987) Consideration and controversies in the selection of radiopharmaceuticals. In Essentials of Nuclear Medicine Science (Edited by Hladik W. B., Saha G. B. and Study K. T.), pp. 75-83. Williams \& Wilkins, Baltimore, Md.

Counsell R. E., Schwendner S. W., Gross M. D., Longino M. A. and McConnell D. S. (1989) Lipoprotein incorporation enhances radioiodinated cholesteryl ester uptake into steroid hormone-secreting tisues. J. Nucl. Med. 30, 1088-1094.

Damle N. S., Seevers R. H., Schwendner S. W. and Counsell R. E. (1983) Potential tumor- or organ-imaging agents XXIV: chylomicron remnants as carriers for hepatographic agents. J. Pharm. Sci. 72, 898-901.

Folch J., Lees M. and Sloane Stanley G. H. (1957) A simple method for the isolation and purification of total lipids from animal tissues. $J$. Biol. Chem. 226, 497-509.
Gibson J. C., Paterniti J. R. and Goldberg I. J. (1984) Measurement of heparin-releasable triacylglycerol lipases. In Lipid Research Methodology (Edited by Story J. A.), pp. 241-286. Liss, New York.

Hock A., Spohr G., Schmitz M., Notohamiprodjo G., Porschen R., Vyska K., Freundlieb C., Shreeve W. W. and Feinendegen L. E. (1986) 17-Iodine-123 iodoheptadecanoic acid for metabolic liver studies in humans. J. Nucl. Med. 27, 1533-1539.

Huettinger M., Corbett J. R., Schneider W. J., Willerson J. T., Brown M. S. and Goldstein J. L. (1984) Imaging of hepatic low density lipoprotein receptors by radionuclide scintiscanning in vivo. Proc. Natl Acad. Sci. U.S.A. 81, 7599-7603.

Jago J. R., Gibson C. J. and Diffey B. L. (1987) Evaluation of subjective assessment of liver function from radionuclide images. $\mathrm{Br}$. J. Radiol. 60, 127-132.

Jansen H. and Hulsmann W. C. (1985) Enzymology and physiological role of hepatic lipase. Biochem. Soc. Trans. $13,24-26$.

Jost R. C. (1987) Metabolic fate of radiopharmaceuticals. In Essentials of Nuclear Medicine Science (Edited by Hladik W. B., Saha G. B. and Study K. T.), pp. 44-50. Williams \& Wilkins, Baltimore, Md.

Kralovic R. C., Zepp E. A. and Cenedella R. J. (1977) Studies of the mechanism of carcass fat depletion in experimental cancer. Eur. J. Cancer 13, 1071-1079.

Levy E., Shafrir E., Ziv E. and Bar-On H. (1985) Composition, removal and metabolic fate of chylomicrons derived from diabetic rats. Biochim. Biophys. Acta 834, 376-385.

Lyon I., Kannon R., Ookhtens M. and Baker N. (1982) Turnover and transport of plasma very-low-density lipoprotein triglycerides in mice bearing Ehrlich ascites carcinoma. Cancer Res. 42, 132-138.

Machulla H. J. and Knust E. J. (1984) Recent developments in the field of ${ }^{123}$ I-radiopharmaceuticals. Nuklearmedizin 3, 111-118.

Masuno $H$. and Okuda $H$. (1985) Decrease in alkaline triglyceride lipase in primary cultured hepatocytes from mice with Sarcoma 180. Lipids 20, 399-403.

Masuno H. and Okuda H. (1986) Hepatic triacylglycerol lipase in circulating blood of normal and tumor-bearing mice and its hydrolysis of very-low-density lipoprotein and synthetic acylglycerols. Biochim. Biophys. Acta 879, 339-344.

Masuno H., Shiosaka T., Itoh Y., Onji M., Ohta Y. and Okuda H. (1985) Hepatic triglyceride lipase and lipoprotein lipase activities in post-heparin plasma of patients with various cancers. Jpn. J. Cancer Res. 76, 202-207.

Mertens J., Vanryckeghem W. and Bossuyt A. (1986) Fast, low-temperature preparation of carrier-free 17-123I-heptadecanoic acid applied for liver and heart scintigraphy. Eur. J. Nucl. Med. 11, 361-362.

Narayan K. A. (1975) Electrophoretic methods for the separation of serum lipoproteins. In Analysis of Lipids and Lipoproteins (Edited by Perkins E. G.), pp. 225-249. The American Oil Chemists Society, Champaign, Ill.

Nilsson-Ehle P. and Eckman R. (1977) Rapid, simple and specific assays for lipoprotein lipase and hepatic lipase. Artery 3, 194-209.

Nomura T., Iguchi A., Matsunga $H$. and Sakamoto N. (1982) The effects of fasting and streptozotocin diabetes on the triglyceride lipase activity of rat liver plasma membranes. Lipids 17, 573-575.

Persson E. and Nilsson-Ehle P. (1990) Release of lipoprotein lipase and hepatic lipase activities. Effects of heparin and a low molecular weight fragment. Scand. J. Clin. Lab. Invest. 50, 43-49.

Redgrave T. G. and Snibson D. A. (1977) Clearance of chylomicron triacylglycerol and cholesteryl ester from the plasma of streptozotocin-induced diabetic and 
hypercholesterolemic hypothyroid rats. Metabolism 26, 493-503.

Sasso G. F., Ceccant M., Di Giovanni M. G., Pisculli M., Romeo M. and Chiarioni T. (1985) Heparin effects on lipid metabolism in healthy people. Pan. Med. 27, 159-163.

Sultan F., Lagrange D., Jansen H. and Griglio S. (1990) Inhibition of hepatic lipase activity impairs chylomicron remnant removal in rats. Biochim. Biophys. Acta 1042, $150-152$.

Takanashi R., Horrobin D. F., Watanabe Y., Kyte V. and Billard V. (1987) Short-term diabetes increases triacylglycerol arachidonic acid content in the rat liver. Biochim. Biophys. Acta 921, 151-153.

Tayck J. A., Istfan N. W., Jones C. T., Hamawy K. J., Bistrian B. R. and Blackburn G. L. (1986) Influence of the Walker 256 carcinosarcoma on muscle, tumor, and whole-body protein synthesis and growth rate in the cancer-bearing rat. Cancer Res. 46, 5649-5654.

Vera D. R., Stadalnik R. C. and Krohn K. A. (1985) Technitium-99m galactosyl-neoglycoalbumin: preparation and preclinical studies. J. Nucl. Med. 26, $1157-1167$.

Wang C. S., Kuksis A. and Manganaro F. (1982) Studies on the substrate specificity of purified human milk lipoprotein lipase. Lipids 17, 278-284.

Weichert J. P., Groziak M. P., Longino M. A., Schwendner S. W. and Counsell R. E. (1986a) Potential tumor- or organ-imaging agents. 27. Polyiodinated 1,3-disubstituted and 1,2,3-trisubstituted triacylglycerols. J. Med. Chem. 29, 2457-2465.

Weichert J. P., Van Dort M. E., Groziak M. P. and Counsell R. E. (1986b) Radioiodination via isotope exchange in pivalic acid. Appl. Radiat. Isot. 37, 907-913. 